\title{
Microbeam Analysis of Irradiated Materials: Practical Aspects
}

\author{
Jérôme Lamontagne, ${ }^{\star}$ Thierry Blay, and Ingrid Roure \\ Commissariat à l'Energie Atomique—Centre de Cadarache, DEN/DEC/SA3C/L2EC, \\ Bât 316-13108 St Paul Lez Durance cedex, France
}

\begin{abstract}
Among the microanalytical techniques, electron probe microanalysis (EPMA) is one of the most powerful. Its performances can be used to provide an accurate characterization. In the present article the differences between the EPMA of highly irradiated materials and standard EPMA are highlighted. It focuses on the shielded EPMA specificities. Then, the article presents the difficulties encountered during the sample preparation and the analysis (mainly due to the radioactive background). In spite of these difficulties, some valuable results can be provided by a shielded EPMA on the in-pile behavior of nuclear irradiated fuel. Some results of specific examples analyzed by EPMA in nuclear fuel research are presented.
\end{abstract}

Key words: shielded EPMA, irradiated nuclear fuel, quantitative radial measurement, X-ray mapping

\section{INTRODUCTION}

The characterization of nuclear fuel and the understanding of its physical and chemical evolution in power reactors are of great importance for the nuclear industry. During irradiation, many fission products (FPs) are produced by reaction between the fissile atoms $(\mathrm{U}, \mathrm{Pu})$ and the neutrons. The behavior of these FPs and their impact on the change of ceramics fuels with increasing burnup have been the subject of numerous studies over the past decades (the formation of fission gas bubbles, fuel pellet swelling, pellet-cladding mechanical interaction, FP distribution depending on whether they are volatile, gas or metal, and so forth).

Several analysis methods have been applied to study FP behavior (Matzke et al., 1989). One of the most common techniques is electron probe microanalysis (EPMA) (Walker, 1999). But EPMA on irradiated nuclear fuel differs markedly from standard EPMA (Walker, 2004). The device must be shielded with heavy metal to protect the operator from radiation exposure and detectors must be shielded to reduce the radiation background.

This article deals with the practical aspects of EPMA as applied to irradiated materials and, more precisely, nuclear fuel. The difficulties encountered in the preparation of the nuclear irradiated fuel sample and during the analysis (mainly due to the radioactive background) are described. In spite of these difficulties, some valuable results on the in-pile behav-

Received July 18, 2006; accepted February 17, 2007.

${ }^{*}$ Corresponding author. E-mail: jerome.lamontagne@cea.fr ior of nuclear irradiated fuel can be provided by a shielded EPMA of which a few specific examples are given at the end of the article.

\section{Sample Preparation}

At the LECA-STAR facility of the French Atomic Energy Commission (CEA), nuclear irradiated fuels come from different reactors (power, experimental, navy). As a consequence of the high radioactivity levels of these samples, sample handling and analyses have to be carried out in a specific environment and with specialized analytical equipment. The nuclear fuel rods are therefore introduced in a shielded room called a "hot cell" (Fig. 1a). All manipulations are carried out using remote manipulator arms. In these hot cells several operations are performed. The rod is cut in order to obtain a 5-mm-thick slice. This sample is embedded in a metallic alloy with a low melting point, to ensure good electrical conductivity, and polished. An illustration of a sample after embedding and polishing is shown in Figure 2. The sample is transported with a shielded transfer cask and arrives in the EPMA cell (Fig. 1b).

In the near future the sample will travel more easily via a pneumatic system. The same sample can be used for EPMA, scanning electron microscopy, and secondary ion mass spectrometry (SIMS) examination (Lamontagne et al., 2006). These three apparatuses are located in the same area, each in different cells with shielded connection tunnels allowing an easy transfer of radioactive material from one device to the other. 


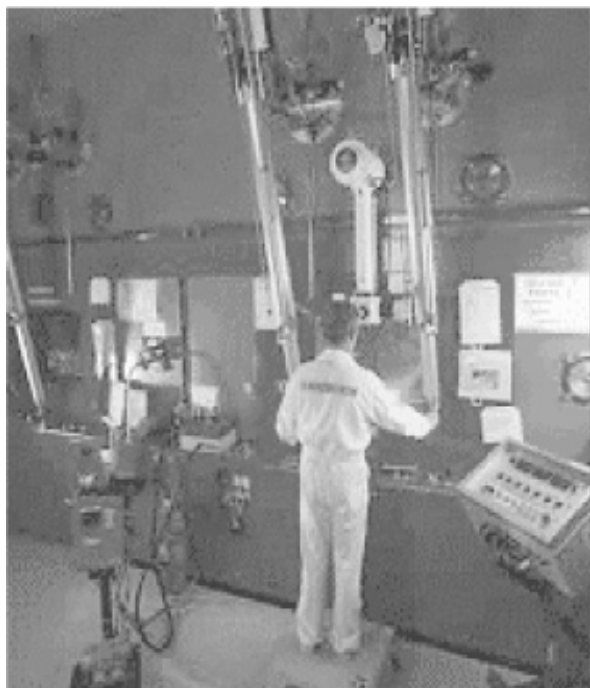

(a)

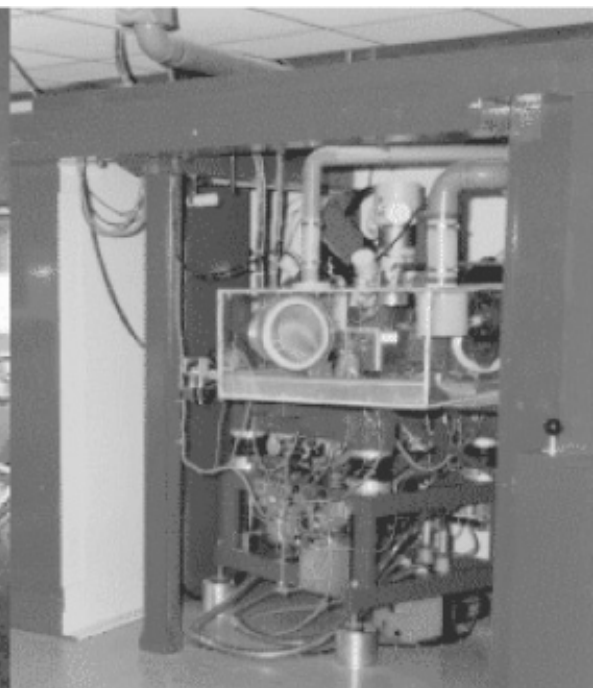

(b)
Figure 1. a: Front view of a hot cell with an operator working with the remote manipulator arms. b: General view of the shielded EPMA and its $\alpha$ box in the dedicated hot cell (the front wall in concrete is moved allowing to see the EPMA).

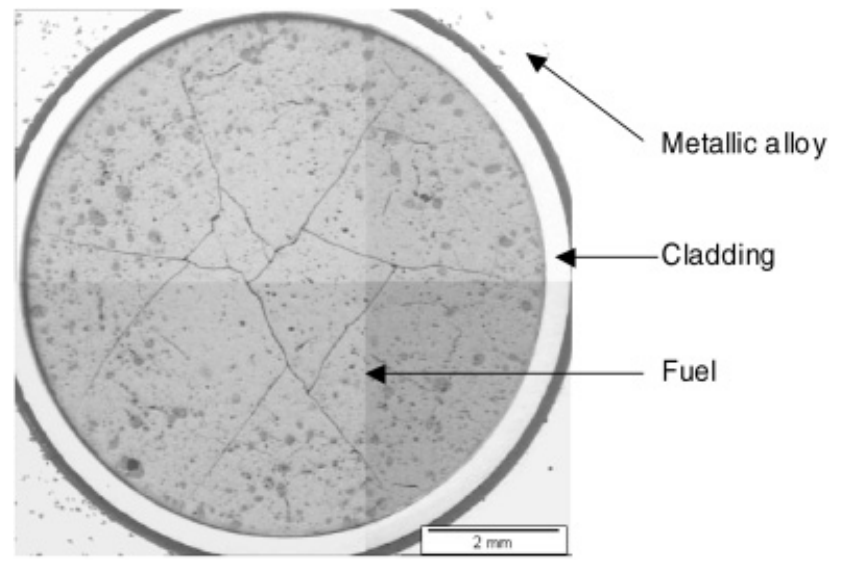

Figure 2. Photograph of the sample after polishing.

\section{The Shielded EPMA}

EPMA is a near surface analysis technique and its spatial resolution is $\sim 1 \mu \mathrm{m}$. It allows a very local quantitative measurement of the FPs on the irradiated fuel and an analysis of elements from Be to Am.

In our laboratory, the EPMA analyses are performed with a shielded CAMEBAX-R (CAMECA) controlled by the XMAS software of SAMx. The EPMA, equipped with 4 WDS spectrometers, is located in a hot cell. It has walls made of concrete and lead. Lead absorbs $\gamma$ radiation emitted by the specimens, located inside the hot cell. The sample manipulation inside the hot cell is performed with remote mechanical manipulators. The operator sees the operation through a thick lead glass window.

The working station is located outside the cell and the cables connecting the electronic and the system go through the wall.
Moreover, in order to avoid a contamination of the hot cell and of the external components of the EPMA by $\alpha$ particles, an " $\alpha$ box" is connected with the EPMA to create a confinement. The sample is taken by the manipulators in the $\alpha$ box and is introduced in the EPMA.

Due to the high activity a shielding consisting of heavy metal is also required inside the EPMA. The system is designed to accept samples emitting $\beta$ and $\gamma$ radiations. The $\gamma$ radiation level can reach $3 \mathrm{Ci}$ at an energy of $0.75 \mathrm{MeV}$.

The radioactive specimen inside the chamber produces such a level of radiation that human beings shall not enter the hot cell. If the operator has to enter the hot cell, the specimen must be removed from the cell and be transferred to another cell. For each maintenance operation (filament exchange, for example), the specimen must be extracted from the EPMA. The maintenance of a shielded EPMA is therefore more difficult than a standard one, which implies an extended analysis time.

\section{EfFect of IrRadiation Background}

Without any protection or shielding, the $\gamma$ radiation emitted by the specimen would produce a high noise level in the detectors of a standard EPMA. Those detectors have to be shielded to obtain accurate and reliable analysis results. The arrangement of the shielding of the counters is illustrated in Figure 3. The Denal (special tungsten alloy) shielding is mounted inside the spectrometer and around each X-ray counter to prevent the $\gamma$ radiation from entering the counter. In the new generation of shielded EPMAs, the sample stage is also shielded. The sample holder is made of Denal in order to protect the rest of the instrument against the specimen radiation and to attenuate the $\gamma$ radiation as close to the specimen as possible. 

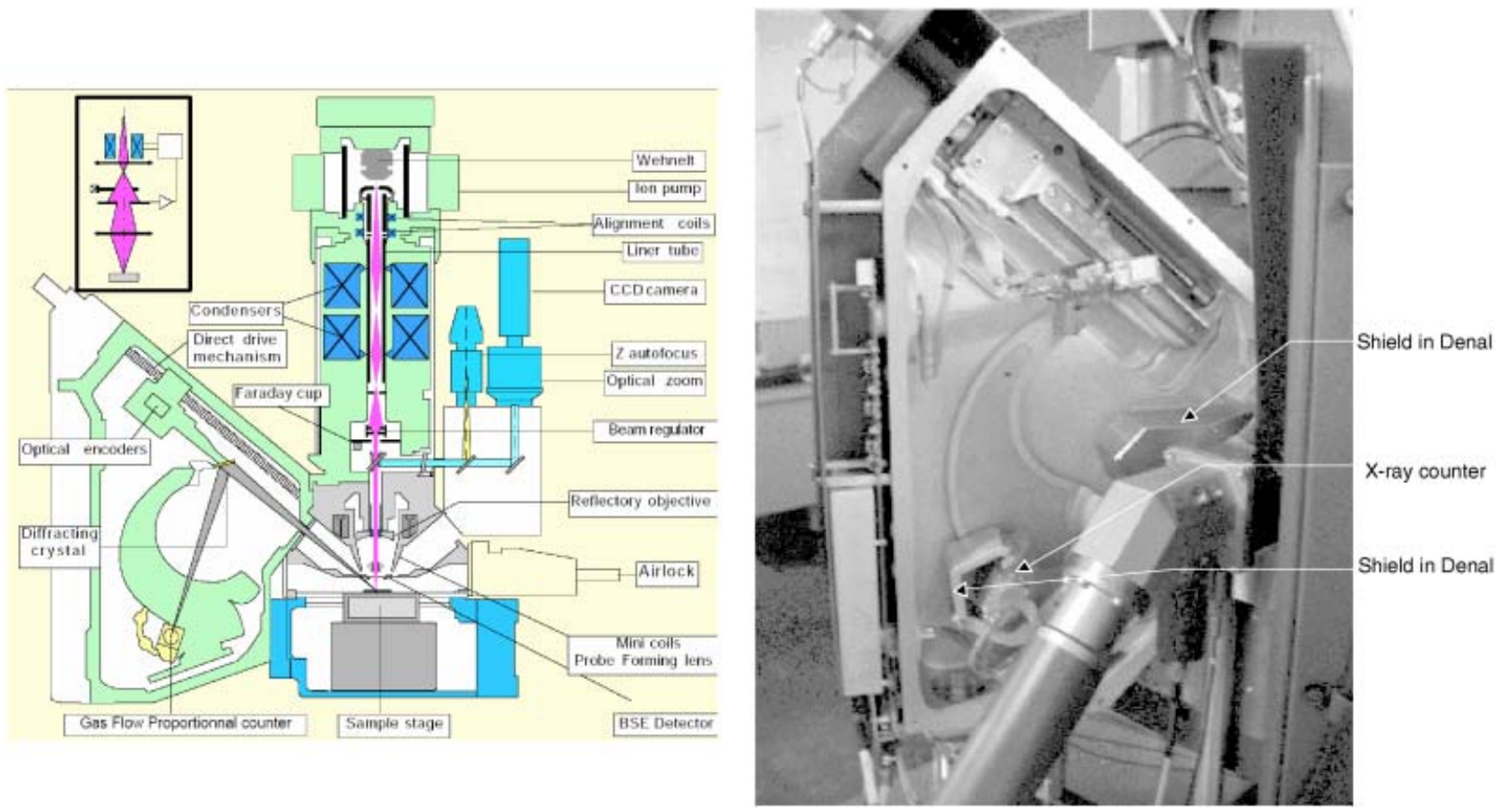

Figure 3. a: Schematic view of an EPMA. b: Detail view of the shielded part of a spectrometer.

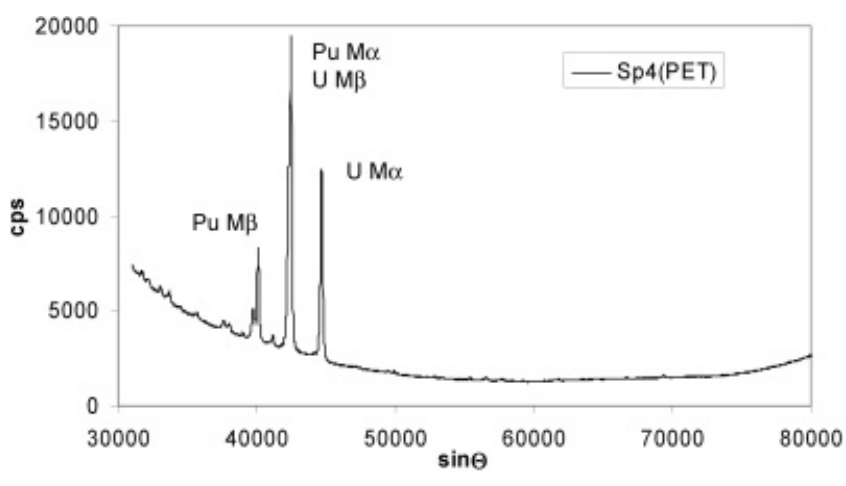

Figure 4. Intensity in counts per second caused by the radioactive sample versus $\sin \theta$ of the spectrometer.

The irradiation background is illustrated in Figure 4, representing the intensity in counts per second due to the radioactive sample versus $\sin \theta$ of the spectrometer. Some characteristic peaks of the abundant elements in the sample are easily observable ( $\mathrm{Pu}-\mathrm{M} \beta, \mathrm{Pu}-\mathrm{M} \alpha, \mathrm{U}-\mathrm{M} \beta, \mathrm{U}-\mathrm{M} \alpha)$. But an important background is also highlighted particularly at low $\sin \theta$ (e.g., when the $\mathrm{X}$-ray counter is nearest to the analysis chamber). To maximize the peak/background ratio, high incident beam currents of $250 \mathrm{nA}$ and high electron beam energy of $15 \mathrm{keV}$ are chosen. Thus, it is possible to obtain acceptable detection limits within reasonable counting times even on highly active samples.

\section{Brief Description of Procedures FOR SOME FPs AnAlyses}

In a standard analysis, several FPs $(\mathrm{Nd}, \mathrm{Xe}, \mathrm{Mo}, \mathrm{Ru}, \mathrm{Te}, \mathrm{Tc}$, $\mathrm{Zr}, \mathrm{Cs})$ are studied to understand the in-reactor fuel behavior. Here, we will focus on two FPs, Nd and Xe (gaseous FP). The characteristic peaks of each element ( $\mathrm{Nd} L \alpha$; Xe $\mathrm{L} \alpha$ ) are illustrated in Figure 5. In this figure, the importance of the irradiation background is highlighted, explaining the relatively important uncertainties for these trace elements. The proportion of each trace element after irradiation in reactor is $\sim 1 \mathrm{wt} \%$. One way to measure the background noise is by doing two symmetrical measurements below and above the peak energy. For Nd, the background noise cannot be measured on both sides of the peak (presence of other lines close to the peak). A pseudo-slope is taken into account. The acquisition time is $10 \mathrm{~s}$ at the peak position and $5 \mathrm{~s}$ at the two background positions. A high peak-tobackground ratio is achieved by the use of a high electron acceleration voltage (15-25 keV) and a high beam current of $250 \mathrm{nA}$. But the low element concentration makes the analysis tricky with an uncertainty level of about $15 \%$.

Moreover, another challenge in the quantification is related to the standards. For nonradioactive elements, reference materials can be commercially acquired. But for $\mathrm{Pu}$ analysis, a homemade standard has to be used. For Xe, a suitable standard for EPMA analysis does not exist. Therefore, the quantitative analysis is generally carried out 

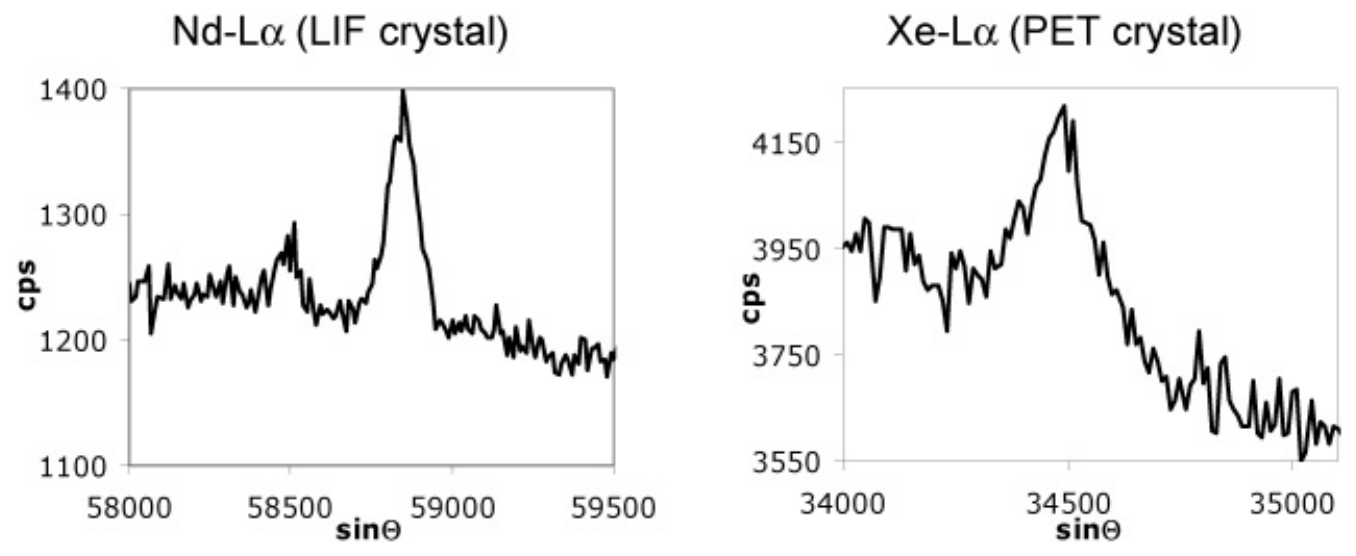

Figure 5. Characteristic peaks of (a) Nd-L $\alpha$ and (b) Xe-L $\alpha$.

(Boidron et al., 1991) using a multicharacterized $\mathrm{UO}_{2}$ (irradiated at low temperature, $25 \mathrm{GWd} / \mathrm{t}(\mathrm{U}))$ standard.

\section{Examples of Current Applications of EPMA to Irradiated Nuclear Fuel}

Some examples are illustrated in this part for the following species: $\mathrm{Pu}, \mathrm{Nd}, \mathrm{Xe}$. EPMA allows us to obtain three principal kinds of results: concentration of the element along a radial measurement, mapping (Friel \& Lyman, 2006) on large areas by stage movement, and mapping on small areas by beam scanning.

\section{Quantitative Radial Measurement}

Figure 6 shows the EPMA Nd and Xe concentration profiles from the periphery to the center of an $\mathrm{UO}_{2}$ fuel pellet.

The Xe profile is compared with the Nd profile (which is generally considered to be directly proportional to the local burnup). The Xe and $\mathrm{Nd}$ profiles are fitted so that the two curves are superimposed when the Xe concentration is equal to its creation value. Three main areas appear in this profile (Noirot et al., 2004). The first one $(0-100 \mu \mathrm{m})$ is located at the periphery of the pellet where the rim effect occurred (i.e., changes of the $\mathrm{UO}_{2}$ structure into high burn-up structure; Ronchi \& Walker, 1980). The second one is located between $100 \mu \mathrm{m}$ and $2000 \mu \mathrm{m}$. In this midradius area, because of the relatively low temperatures, no gas bubbles are formed during irradiation. As a consequence, the Xe measured with EPMA is equal to the quantity created during irradiation (about $0.8 \%$ in mass). The third area is located at the center of the pellet. In this area, there is a decrease in Xe concentration. In both the central part and the rim area, the level of the measured Xe is lower than the created one. Indeed, two decades ago, Ronchi and Walker (1980) showed that the clustering of fission gas and the formation of bubbles result in a loss of signal in EPMA

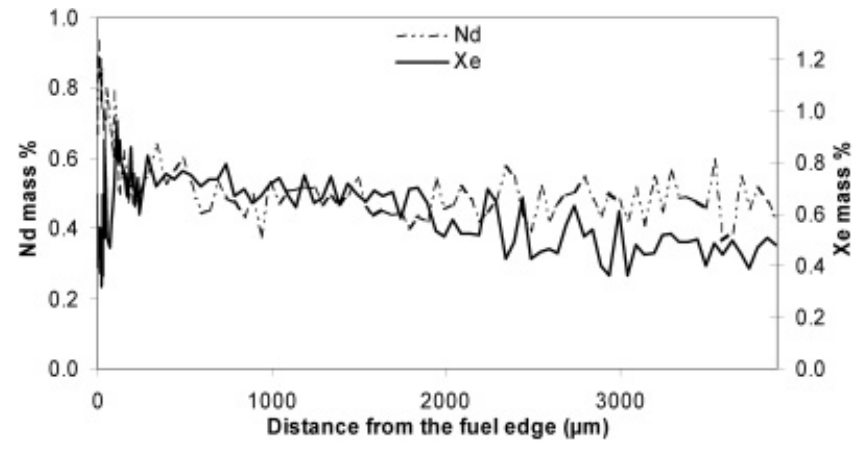

Figure 6. EPMA radial measurements of the Xe compared to Nd.

analyses. The difficulty in these EPMA measurements, clearly explained by Verwerft (2000), is that the characterization is close to the sample surface $(\sim 1 \mu \mathrm{m}$ depth) and therefore, when gas precipitation in bubbles occurs, the bubbles opened by the preparation at the surface of the sample release their gas. Moreover, most of the gas in the closed subsurface pores cannot be accessed without increasing the beam acceleration. Thus the EPMA cannot measure directly the amount of gas released during reactor operations.

\section{Mapping on a Large Area by Stage Movement}

The ceramics used as fuel in some nuclear power plants are made with a mixed oxide of uranium and plutonium. It is called MOX (mixed oxide) and usually contains between 4 and $9 \mathrm{wt} \%$ of $\mathrm{Pu}$. One of the major parameters of interest for the nuclear industry is the level of homogeneity of the $\mathrm{Pu}$ distribution in the fuel.

Using EPMA, the level of homogeneity in a fuel pellet is evaluated by characterizing Pu distribution. Large area X-ray maps of $\sim 1 \mathrm{~mm}^{2}$ in size are recorded to obtain information that is characteristic of the sample as a whole. If the $\mathrm{Pu}$ in the sample is heterogeneously distributed, restricting the investigations to small areas could lead to results that are 


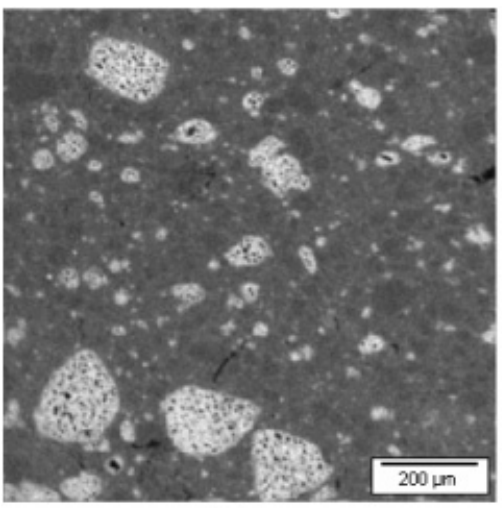

(a) $\mathrm{Pu}$

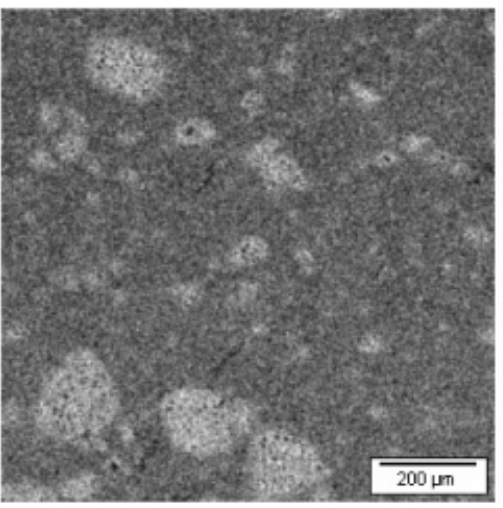

(b) $\mathrm{Nd}$

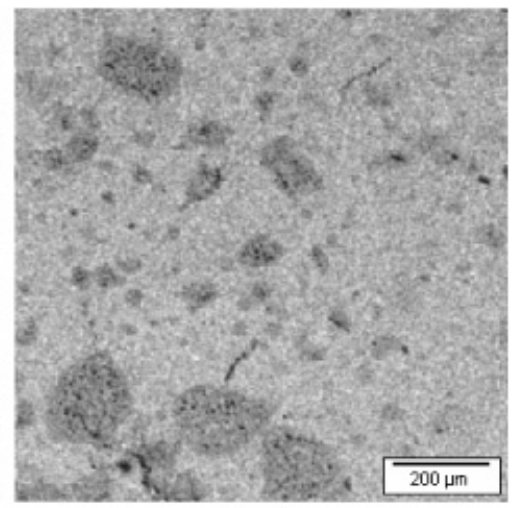

(c) $\mathrm{Xe}$

Figure 7. Large areas mapping $\left(1 \mathrm{~mm}^{2}\right)$ of (a) $\mathrm{Pu},(\mathbf{b}) \mathrm{Nd}$, and (c) $\mathrm{Xe}$.

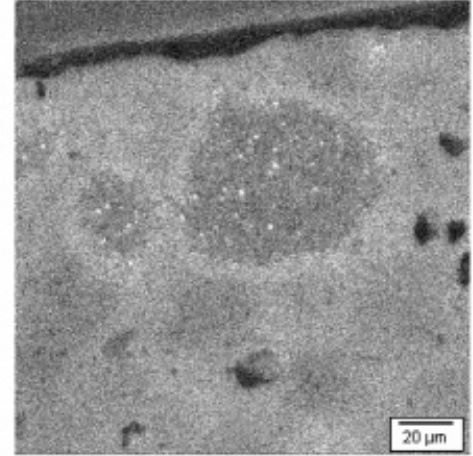

(a)

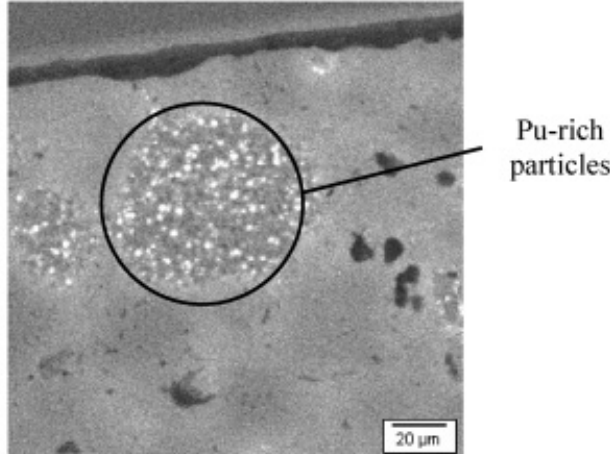

(b)

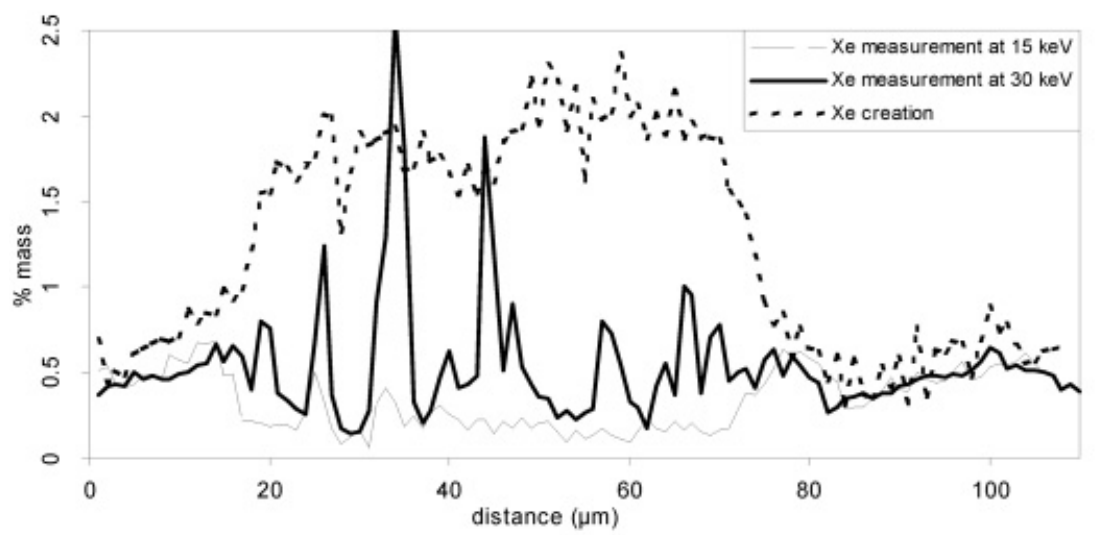

(c)

Figure 8. EPMA mapping $(166 \mu \mathrm{m} \times 166 \mu \mathrm{m})$ of $\mathrm{Xe}(\mathbf{a})$ at $15 \mathrm{keV}$ and (b) at $30 \mathrm{keV}$, and (c) quantitative analysis through the Pu-rich particle.

not representative of the entire pellet. Figure 7 a shows an example of a large area compositional Pu X-ray map obtained by wavelength dispersive electron probe microanalysis that can be used to characterize the $\mathrm{Pu}$ distribution in nuclear fuel pellets (Bremier et al., 2003).
From large areas compositional $\mathrm{Nd}$ and Xe X-ray maps (Fig. $7 b, c)$ and after some images analysis, the fraction of restructured surface can be determined. These two maps are quite noisy due to the low abundances of these two species (in the range of $0-2 \mathrm{wt} \%$ ). 


\section{Mapping by Beam Scanning}

The mapping by beam scanning concerns maps of restricted areas (size ranging from 30 to $200 \mu \mathrm{m}^{2}$ ). The objective of making such restricted area maps is to obtain information with higher lateral resolution. Figure 8a,b presents Xe X-ray maps at $15 \mathrm{keV}$ and $30 \mathrm{keV}$, acquired across an area containing a $\mathrm{Pu}$-rich particle in the periphery of the pellet.

The Xe consists of a gray background with white and black dots. The gray background indicates an almost homogeneous Xe concentration generally attributed to the Xe included in the $\mathrm{UO}_{2}$ matrix (Fisher et al., 2002; Lamontagne et al., 2004). The white and black dots can be associated with gas bubbles, the white dots corresponding to bubbles filled with Xe and the black dots to bubbles emptied of their gas during the preparation as already explained.

The volume of sample involved in the EPMA measurement is not large and does not extend very deep under the surface. When the bubbles are small, the ratio between the lost gas and the gas involved in the measurement is low and can be neglected. When bubbles grow to a size of more than 1 or $2 \mu \mathrm{m}$ in diameter, this ratio increases. Thus, most of the precipitated gas can no longer be detected by EPMA. The beam penetration depth increases with the high voltage of the electron beam, which means that the proportion of lost gas is also a function of this high voltage. The observations at different high voltages show different results. The quantity of the bubbles not opened by the preparation and detectable by EPMA increases with the high voltage (Friel \& Lyman, 2006). Figure 8c presents the quantitative analysis of the Xe concentration through the Pu-rich particle at $15 \mathrm{keV}$ and $30 \mathrm{keV}$. The creation profile on this figure is an estimation given by the $\mathrm{Nd}$ measured relative profile and by the overall Xe calculation at this level of the rod.

Depending on the high voltage of the incident beam, the EPMA detection of Xe increases. Each peak corresponds to a filled gas bubble under the sample surface. When compared to the Xe creation, the lack in the measurement is therefore the result of a combination of factors including the actual in-reactor gas release, the amount of precipitated gas, and the size of the formed bubbles. It is consequently difficult to understand it fully and directly. The amount of gas that goes undetected in the EPMA analysis is considered to be a maximum value of the gas available for release. To determine the amount of gas released, a coupled EPMASIMS analysis is helpful (Lamontagne et al., 2004; Desgranges \& Pasquet, 2004).

\section{CONCLUSION}

When analyzing nuclear irradiated fuel with EPMA, several difficulties are encountered: sample preparation, manipulation via the remote manipulator arms, shielding of the
EPMA, irradiation background, and the choice of the standards. In spite of these difficulties it was shown that EPMA is one of the principal microanalytical techniques and allows us to obtain valuable information on irradiated fuel. The behavior of the FPs of the fuel in the reactor can be studied by three principal methods: concentration of the element along a radial measurement, large area mapping by stage movement, and mapping by beam scanning.

\section{ReFERENCES}

Boidron, M., Tourasse, M., Boussard, F., Piron, J.-P. \& PasQUET, B. (1991). Microprobe measurement calibration of absorbed xenon in a PWR fuel. In Proceedings of the International Topical Meeting on LWR Fuel Performance, Avignon, France, April 21-24. La Grange Park, IL: American Nuclear Society.

Bremier, S., HaAs, D., Somers, J. \& Walker, C.T. (2003). Large area quantitative $\mathrm{X}$-ray mapping of $(\mathrm{U}, \mathrm{Pu}) \mathrm{O}_{2}$ nuclear fuel pellets using wavelenght dispersive electron probe microanalysis. Spectrochim Acta B 58, 651-658.

Desgranges, L. \& Pasquet, B. (2004). Measurement of xenon in uranium dioxide $\left(\mathrm{UO}_{2}\right)$ with SIMS. Nucl Instrum Meth Phys Res B 215, 545-551.

Fisher, S.B., White, R.J., Cook, P.M.A., Bremier, S., Corcoran, R.C., Stratton, R., Walker, C.T., Kivision, P. \& Palmer, I.D. (2002). Microstructure of irradiated SBR MOX fuel and its relationship to fission gas release. J Nucl Mater 306, 153-172.

Friel, J.J. \& Lyman, C.E. (2006). X-ray mapping in electron-beam instruments. Microsc Microanal 12, 2-25.

Lamontagne, J., Desgranges, L., Valot, Ch., Noirot, J., Blay, Th., Roure, I. \& Pasquet, B. (2006). Fission gas bubbles characterisation in irradiated $\mathrm{UO}_{2}$ fuel by SEM, EPMA and SIMS. Microchim Acta 155, 183-187.

Lamontagne, J., Noirot, J., Desgranges, L., Blay, Th., PasQUET, B. \& Roure, I. (2004). Detection of gas bubble by SIMS in irradiated nuclear fuel. Microchim Acta 145, 91-94.

Matzke, H.J., Blank, H., Coquerelle, M., Lassmann, K., Ray, I.L.F., Ronchi, C. \& Walker, C.T. (1989). Oxide fuel transients. J Nucl Mater 166, 165.

Noirot, J., Noirot, L., Desgranges, L., Lamontagne, J., Blay, TH. \& PAsquet, B. (2004). Fission gas inventory in PWR high burnup fuel: Experimental characterisation and modelling. In Proceedings of the 2004 International Meeting on LWR Fuel Performance, Orlando, Florida, September 19-22. La Grange Park, IL: American Nuclear Society.

Ronchi, C. \& WALker, C.T. (1980). Determination of xenon concentrations in nuclear fuels by electron microprobe analysis. J Phys D 13, 2175.

Verwerft, M. (2000). Multiple voltage electron probe microanalysis of fission gas bubbles in irradiated nuclear fuel. $\mathrm{J} \mathrm{Nucl}$ Mater 282, 97-111.

WALKER, C.T. (1999). Electron probe microanalysis of irradiated nuclear fuel: An overview. J Anal Atom Spectrom 14, 447-454.

WALKER, C.T. (2004). Electron probe microanalysis of actinide elements. Microsc Microanal 10, 898-899. 